\title{
वैदिक काल में जल प्रबंधन
}

राकेश कुमार शर्मा एवं महेश कुमार सहगल

सारांश

प्राचीन भारतीय वैदिक संस्कृति के अध्ययन से ज्ञात होता है कि वैदिक काल में जल प्रबंधन का कार्य वृहत् एवं अति उत्तम विधियों से किया जाता था। पौराणिक मान्यताओं के अनुसार जल की उत्पत्ति 'नर' (पुरूष=परब्रह्य) से हुई है। अतः उसका प्राचीन नाम 'नार' है। वह (नर) 'नार' में ही निवास करता है। अतः उस नर को नारायण कहते हैं। विष्णु पुराण के अनुसार संसार के सृष्टि-कर्ता ब्रह्मा का सबसे पहला नाम 'नारायण' है तथा दूसरे शब्दों में भगवान का जलमय रूप ही संसार की उत्पत्ति का कारण है। 'जल ही जीवन है' इसीलिए जल की बर्बादी को रोकना, समुचित जल प्रबंधन का कार्य पर्याप्त मात्रा में करना और भी महत्वपूर्ण हो जाता है। प्रस्तुत शोध पत्र में वैदिक काल में किये गये जल प्रबंधन के कार्यो की व्याख्या है। मनुष्य इस सर्व सिद्ध सूत्र को पूर्णतः भुला बैठा है कि जल नहीं तो जीव या जीवन कुछ नही होगा; जबकि भारत देश में आज भी यत्र-तत्र वैदिक काल की जल संरक्षण और संभरण की विभिन्न व्यवस्थायें देखी जा सकती हैं और उन्हीं आयामों को अल्प परिवर्तनों के साथ अपना कर वर्तमान पर्यावरणीय समस्याओं से मुक्ति पायी जा सकती है। वैदिक काल में जल प्रबंधन का कार्य प्राकृतिक और कृत्रिम दोनों ही स्रोत से करते थे। अतः वैदिक काल के जल प्रबंधन की आचार संहिता एवं उसके क्रियान्वयन के तौर तरीकों की खोज का अध्ययन करना भी आवश्यक हो जाता है। वास्तव में किसी भी राष्ट्र की अर्थव्यवस्था की धुरी पेय जल एवं सिंचाई प्रबंधन होता है जो कि जल प्रबंधन की मूलभूत विषय वस्तु है, क्योकि इस पर ही कृषि, औद्योगिक एवं तकनीकि प्रगति निर्भर करती है।

कूट शब्द : जल, वैदिक काल, जल प्रबंधन, कृत्रिम एवं प्राकृतिक स्रोत

वैदिक साहित्य में जल तत्व एवं उसके प्रकार के अनुसार निघण्टुकार ने केवल जल वाचक पदों का परिगणन ही नहीं किया वरन् जिसमें जल तत्व समाहित है, जो तरल रूप हैं, उन सबका इस गण में समाहार भी किया गया है (मिश्रा, 2011, पृ. 13-14)। इनकी संख्या एक सौ एक है वे है- अर्ण, क्षोद:, क्षद्य, नभः, अम्भः, कवन्धम्, कबंधम्, सलिलम्, वा:, वानम्, घृतम्, मधु, पुरीषम्, पिपलम्, क्षीरम्, विषम्, रेतः, कशः, जन्म, बृबूकम, बुसम्, तुग्रद्या, बुर्बरम्, सुक्षेम्, धरूणम्, सिरा, अररिन्दानि,ध्वस्मन्वत्, जामि, आयुधानि, क्षपः, अहिः, अक्षरम् स्रोतः, तृप्ति, रसः, उदकम्, प्रयः, सरा:, भेषजम्, सहः, शवः, यहः, ओजः सुखम्, क्षत्रम, आवयाः, शुभम्, यादुः, भूतम, भुवनम्, भविष्यत्, महत्, आपः, व्योम, यशः, महः, सर्णीकम्, सतीनम्, गहनम्, गभीरम्, गम्भम्, ईम्, अन्न्, हविः, सद्य, सदनम, योनिः, सत्यम्, तीरम, रयिः, सत्, पूर्णम्, सर्वम्, अक्षितम, बर्हिः, नाम, सर्पि, अपः, पवित्रम्, अमृतम्, इन्दुः, हेम, स्व: सर्गा:, शम्बरम्, अम्वम्, वपु:, अम्बु, तायम्, कृपीटम्, शुक्रम्, तेज: स्वधा, वारि, जलम्, जलाषम्, इदम् (शास्त्री, 2004, पृ. 1)। मणि (2008) के अनुसार जल एक महत्वपूर्ण प्राकृतिक संसाधन है। समस्त मानव सभ्यता मीठे जल स्रोतों पर ही निर्भर रही है। मानव इन जल स्रोतों का विभिन्न प्रकार से उपभोग करता आया है किन्तु वर्तमान में उपभोग की अप्रत्याशित वृद्धि से जल संसाधनों की उपेक्षा की गई है (पृ. 9)। मिश्रा (2011) के अनुसार जल का महत्व शब्दों में व्यक्त नहीं किया जा सकता है। यह अनमोल पेय पदार्थ थकान को दूर करने वाला, प्यास को दूर
करने वाला, भोजन को पचाने वाला, बलदायक एवं शरीर में रस प्रदान करने वाला है। मानव की मूलभूत आवश्यकताओं में रोटी, कपड़ा और मकान है परन्तु यह सभी जल की आवश्यकता के सामने अति सूक्ष्म है। इसीलिए संसार की प्रत्येक वस्तु का मूल्य आंका जा सकता है, किन्तु पानी सबसे मूल्यवान पदार्थ है। जिस प्रकार पोषक तत्वों से व्यक्ति का संपूर्ण विकास हो जाता है वैसे ही जल की समुचित उपलब्धता से कृषि की उपज छ: गुना अधिक हो जाती है (पृ. 23)।

खन्ना (2013) वेद, पुराण, महाभारत, एवं वृहत संहिता आदि का संदर्भ दे कर लिखते हैं कि वर्षा के जल, भूमिगत जल एवं अन्य स्रोतों का उपयोग सार्थक रूप से किया जाना चाहिए (पृ. 11)। जल विहीन होने पर सम्पूर्ण ब्रह्मांड की वनस्पतियाँ एवं जीवों का अस्तित्व संभव ही नहीं है। वेदों में जल के एक सौ से अधिक पर्यायवाची शब्द दिये गये हैं; इन पर्यायवाची शब्दों में जल की महत्ता और जल क्या है? इस पर भी प्रकाश डाला गया है जैसे- जल रस, भेषज, अमृत, विष नाशक, पेय पदार्थ, जीवन, आदि। इसके महत्व के अध्ययन से ज्ञात होता है कि जल समस्त वनस्पतियों तथा जीवों के जीवन का आधार है, अर्थात जल ही जीवनदायनी शक्ति है (पृ. 12)।

विद्वानों के अनुसार जल की तुलना किसी अन्य वस्तु से नहीं की जा सकती है। जल मनुष्य का जीवन ही नहीं अपितु समस्त संसार का जीवन है। जल नहीं तो कल नही; इसीलिए 
जल का महत्व सर्व समाज को समझना चाहिए तथा जल प्रबंधन के लिए सदैव ही तत्पर रहना चाहिए।

\section{जल प्रबंधन}

प्राचीन भारतीय मनीषियों के अनुसार, सृष्टि का निर्माण पंच तत्वों के निर्माण से हुआ है। यह तत्व जल, आकाश, पृथ्वी, वायु एवं अग्नि है एवं इनमें भी जल सर्वाधिक अमूल्य प्राकृतिक उपहार है। अतः जल के बिना मानव जाति भी नहीं, अपितु समस्त जीव जन्तु एवं वनस्पत्तियों का अस्तित्व ही संभव नहीं है। यही कारण है कि जल प्रबंधन का अर्थ और महत्व समझना मानव जगत के लिए अति महत्वपूर्ण हो जाता है। इसलिए संपूर्ण मानव जगत के लिए जल प्रबंधन अति आवश्यक है। शुद्ध जल का भण्ड़ारण हमारे ब्रह्याण्ड़ में सीमित होने, अनेकों जल प्रदूषण और जल की बर्बादी के कारण जल प्रबंधन का कार्य और भी अधिक महत्वपूर्ण हो जाता है। प्रारम्भिक काल में मानव इतना सभ्य नहीं था। उसके रहने, खाने-पीने, पहनने आदि की सब आदतें आज से सर्वथा भिन्न थीं। पुरातन काल में धीरे-धीरे लोगों का झुण्ड एक जगह अपना घर बनाकर एकत्रित होकर रहने लगा। कालांतर में यही झुण्ड गांवों व नगरों का रूप धारण करने लगे एवं इनका निर्माण बड़े-बड़े तालाबों, झीलों, नदियों के किनारों पर ही हुआ। यहाँ तटों के किनारे लोगों को पानी सुलभता से उपलब्ध हो जाता था। यहीं से जल प्रबंधन की नींव भी पड़ी क्योंकि इन जल स्रोतों का उपयोग मानव एवं पशु एक साथ करते थे। अतः धीरे-धीरे स्वच्छता के महत्व को समझा जाने लगा था। जल प्रबंधन का अर्थ जल की बरबादी तथा जल प्रदूषण को पूर्णतः रोकने से है। जल संकट को देखते हुए मानव जाति के लिए जल प्रबंधन का कार्य अनिवार्य हो जाता है क्योंकि वर्षा का जल हर समय उपलब्ध नहीं हो सकता।

वर्तमान जल संकट के विषय में पटेरिया व अन्य (2013) के अनुसार मानव ही जल संकट को पैदा कर रहा है। औद्योगिकों द्वारा अत्यधिक मात्रा में जल का दोहन, जनसंख्या वृद्धि, पर्यावरण क्षति, पेड़ों की अत्यधिक कटाई, जल प्रदूषण आदि समस्याओं को देखते हुए जल प्रबंधन को कार्यान्वित करना और भी अधिक महत्वपूर्ण हो गया है। जल की कमी से कृषि और प्रकृति सभी प्रभावित होते हैं एवं जल की कमी जीव संरक्षण में भी बाधक है (पृ. 231-35)।

मिश्रा (2011) भी लिखते हैं कि वर्तमान जल संकट के लिए जनसंख्या वृद्धि एक बड़ा कारण है। इसके अलावा नगदी खेती, औद्योगीकरण, शहरीकरण, पानी की बर्बादी, आधुनिकीकरण, अत्यधिक भूमिगत जल का दोहन, बड़े पैमाने पर पेड़ों की कटाई, बढ़ता जल प्रदूषण, ग्लोबल वार्मिंग आदि जल संरक्षण की समस्याओं को और अधिक बढ़ावा दे रही हैं। इसीलिए जल
प्रबंधन का कार्य और भी अधिक आवश्यक हो जाता है (पृ. 52-56)।

\section{जल प्रबन्धन की महत्ता}

जल के अर्थ एवं महत्व को समझने के पश्चात् ज्ञात होता है कि जल प्रबंधन का महत्व इसीलिए आवश्यक है क्योंकि जल की बर्बादी पर नियंत्रण हो सकेगा। पर्याप्त मात्रा में स्वच्छ पेय जल की उपलब्धता हो सकती है। जल संरक्षण के प्रति जागरूकता बढ़ेगी एवं वर्षा जल संग्रहण को प्रोत्साहन मिलेगा एवं साथ-साथ भूमिगत जल स्तर ऊँचा होगा। औद्योगिक क्षेत्र में जल समस्याओं का निवारण हो सकेगा। जल प्रदूषित एवं बर्बाद करने वालों को अपराधी की श्रेणी में रखा जा सकेगा और ये अति महत्वपूर्ण प्रक्रिया जल प्रबंधन से उजागर हो सकेगी। शुद्ध जल के रख-रखाव एवं उसे लम्बे समय तक सुरक्षित रखना, जल की मृदुता और गुणवत्ता बनाएं रखना, जल को विभिन्न और सुलभ स्रोतों से प्राप्त करना; यह सब बिन्दु जल प्रबंधन के क्षेत्र में आते हैं। अतः जल प्रबंधन वनस्पति जीव एवं सृष्टि संचालन सर्व के प्रति परम् आवश्यक है। वैदिक काल में कृषि व्यवसाय अर्थव्यवस्था की रीढ़ की हड्डी थी। वैदिक काल पूर्णतः ज्ञान विज्ञान का काल रहा है। उस समय प्रयुक्त जल प्रबंधन के कार्यों की सुदृढ़ विधियों के विषय में जानकारियां उपलब्ध कराना तथा उनके स्रोतों की विभिन्नता को प्रदर्शित करना प्रस्तुत शोध पत्र का मुख्य उदेश्य है।

\section{जल प्रबन्धन की व्यवस्था}

जल प्रबन्धन की व्यवस्था वैदिक काल 1500 ईसा पूर्व से 1000 ईसा पूर्व तक एवं उत्तर वैदिक काल 1000 ईसा पूर्व से लेकर 600 ईसा पूर्व तक है। जल प्रबंधन के विषय में हम यह जानने का प्रयास करेगें कि वास्तव में वैदिक कालीन समाज में शुद्ध एवं ताजे पेय जल, घरेलू उपयोग में प्रयुक्त होने वाला जल, पशुपालन एवं कृषि कार्यो में प्रयोग होने वाले जल हेतु तत्कालीन समाज के लोग जल की क्या और कैसी व्यवस्था रखते थे। इस तथ्य में कोई आश्चर्य की बात नहीं है कि सम्पूर्ण वैदिक समाज पूर्णतः ग्रामीण समाज था तथा कृषि और पशुपालन ही तत्कालीन समाज की आजीविका के स्रोत थे। वैदिक काल में कृषि मुख्य व्यवसाय होने के कारण ही ऋग्वेद, यजुर्वेद, और अर्थववेद में कृषि की उन्नति के लिए विविध रूप में ईश्वर से प्रार्थनाएं की गई हैं। जैसे जल-वर्षा हेतू, कृषि की जंगली पशुओं से सुरक्षा हेतू एवं अनेक प्राकृतिक आपदाओं से रक्षा हेतू, भी यज्ञों के माध्यम से वैदिक कालीन लोगों ने अनेकों प्रार्थनाएं की हैं (यजुर्वेद, 22/22)। जल प्रबंधन के संकेत हमें ऋग्वेद काल से ही मिलने लगे हैं। ऋग्वेद में जल को औषधि एवं जीवन का आधार बताया गया है (ऋग्वेद, $1 / 23 / 19)$ | ऋग्वेद में शुद्ध जल को 
स्वास्थ्य, धन शक्ति, लम्बी आयु और अमरतत्व की प्राप्ति का दाता कहा गया है (ऋग्वेद, $1 / 23 / 20$ )। अतः जल का समुचित प्रबंधन करना परमावश्यक है।

प्रकृति के समस्त उपहारों में जल ही एक ऐसा अमुल्य उपहार है जो हमें समस्त ब्रह्माण्ड़ में तीन अवस्थाओं में मिलता है जैसे- गैस (भाप), ठोस (ग्लैशियर) और तरल (भूमिगत जल) के रूप में। नदियों को आधार बनाकर वैदिक युगीन लोग जल प्रबंधन का कार्य किया करते थे। नदियों और नहरों का उल्लेख अनेक बार हुआ है। नदियों के लिए सिंधुनान शब्द एवं नहरों के लिए कुलियां नामक शब्द का उल्लेख हुआ है (ऋग्वेद, $4 / 33 / 7)$ ।

ऋग्वेद के अर्त्तगत जल प्रबंधन हेतू चिंता दिखाई देती है। ऋग्वेद के एक आख्यान के अनुसार वत्र नामक राक्षस ने सम्पूर्ण ब्रह्याण्ड का जल जैसे वर्षा का जल, नदियों का जल, झरनों का जल, भूमिगत जल एवं तालाबों और समस्त जलाशयों के जल को अपनी शक्ति के द्वारा बाधित कर दिया था। समस्त ब्रह्माण्ड़ के जीव जन्तुओं, वनस्पतियों के जीवन संकट में आने से इन्द्र देव ने वत्र नामक राक्षस की ठोड़ी पर अपने वज्ञ से प्रहार करके उसे मृत्युलोक पहुंचाया। इस प्रकार से इन्द्र देव ने सभी प्रकार के जल को वत्र नामक राक्षस से मुक्त करा कर सभी प्रकार की वनस्पति और समस्त जीव जगत की रक्षा की (ऋग्वेद, $7 / 110 / 3 ; 10 / 50 / 31 ; 10 / 105 / 3)$ ।

\section{जल के स्रोत एवं प्रबंधन विधियाँ}

जल प्रबंधन की वैदिक कालीन तकनीकी में जल संरक्षण एवं प्रबंधन का कार्य सम्पूर्ण समाज का था और वह उनकी संस्कृति का एक अभिन्न अंग था जिसका प्रमाण हमें यजुर्वेद के सोलह अध्याय के सैंतीसवें मंत्र में मिलता है। आर्थिक, सामाजिक एवं नवीन अन्वेषणों तथा जल प्रबंधन के स्रोतों एवं प्रविधियों के माध्यम से जल प्रबंधन का कार्य निष्पादित किया जाता था (यजुर्वेद, 16/37)। वैदिक काल में जल प्रदूषित अथवा बाधित करना जघन्य अपराध माना जाता था जिसके लिए मृत्यु दण्ड देने का प्रावधान था। इसका साक्ष्य उक्त पंक्तियों में दिया गया है।

सांस्कृतिक रूप को तकनीकी कहना शायद उचित नहीं लगता किन्तु यहां सटीक इसलिए है क्योंकि वैदिक कालीन समाज जल की पूजा करता था। यही कारण है कि तत्कालीन समाज के लोग जल को दुरूपयोग एवं दूषित होने से बचाते थे। संभवतः वैदिक काल में जल प्रबंधन हेतु एक पृथक् विभाग भी रहा होगा जिसका प्रमाण इन्द्र द्वारा वत्र नामक राक्षस को मृत्युदंड देने एवं जल को मुक्त कराने से स्पष्ट होता है। शुद्ध जल को दूषित होने से बचाना, व्यर्थ में न बहाना एवं किसी भी प्रकार की हानि नहीं पहुंचाना आदि धारणायें सम्पूर्ण समाज में उत्पन्न की
गयी होगी। जल प्रदूषित करने वाला जघन्य अपराधी माना जाता था और पुरातन कृत्रिम, प्राकृतिक जल स्रोतों का जीर्णोद्धार भी कराते थे। नदियों के पानी को काटकर नहरों की खुदाई द्वारा दूरस्थ स्थानों पर जल को ले जाने के साक्ष्य भी मिलते हैं। यज्ञों द्वारा वर्षा कराने के भी ऋग्वेद में मंत्रों के उल्लेख हैं (गुप्ता, 2011, पृ. 190)।

वैदिक काल का वृहद् ज्ञानकोष वेदों में निहित अपार प्रज्ञा सामग्री को ही माना जाता है। वस्तुतः वैदिक-युग की तत्कालीन सामान्य संस्कृति ही वर्तमान में वैदिक संस्कृति के रूप में मान्य है। भारत की प्राचीनतम् निधि वेद है। वेदों में जितना वर्णन इन्द्र या अन्य जल के अधिष्ठाता देवताओं का हुआ है, उतना सब मिलाकर अन्य देवताओं का नहीं हुआ है। वेदों में जल तत्व के सम्यक ज्ञान से अन्तरिक्ष लोक घ्युलोक के बहुत से जटिल और अनसुलझे रहस्य भी उद्धघाटित हो सकते हैं।

अस्वडन्तरमृतमफु भेषमपामुत प्रशस्यते। देवाभवत वाजिन: वाजिनः // ( ऋगेद, 1/23/19)

इस श्लोक के अनुसार जल में अमृतोपम एवं औषधीय गुण हैं। हे देवों आप जलों की प्रशंसा में उत्साह प्राप्त करें।

जल के गुणों के विषय में भी विस्तृत रूप से चर्चा की गई है और बताया गया है कि शुद्ध जल हमारे शरीर के समस्त रोगों को नष्ट करता है। जल एक सशक्त औषधी है और इसीलिए शुद्ध जल की प्राप्ति हेतु ही इस सूक्त में जल के औषधीय गुणों के गुणगान करते हुए ही यज्ञों में उपस्थित होने का आहवान करते हैं। ऐसे जलों को सुरक्षित रखना भी यज्ञों के द्वारा आरम्भ हुआ जो कि जल प्रबंधन का एक अभिन्न अंग है।

ऋग्वेद के प्रथम मंण्डल के ही बत्तीसवें सूक्त का प्रथम मंत्र इन्द्र देव को समर्पित है जो कि निम्नवत् है:-

इन्द्रस्य नु वीर्याणि प्र वोच यानि चकार प्रथममानि वज्री । अहन्नहिमत्वपस्ततर्द प्र पक्षणा अभिनत्पर्वतानाम्// (ऋग्वेद, 1/32/1) इस मंत्र में इन्द्र देव के जल प्रबंधन हेतु किये गये कार्यो का वर्णन है एवं समस्त प्रकार के जलों की समस्याओं को नष्ट करके उन्हें स्वतंत्र रूप से कार्यन्वयन करने की शक्ति प्रदान की है अर्थात मेघों कों विर्दीण कर पानी बरसाने वाले एवं पर्वतीय नदियों के तटों को निर्मित करने वाले वज्जधारी पराकमी, इन्द्रदेव के कार्य वर्णनीय हैं। उन्होंने जो वीरतापूर्वक कार्य किये हैं वे यही हैं।

ऋग्वेद के प्रथम मण्डल के पहले एवं तेईसवें मंत्र के अनुसार देवता इन्द्र ने जल प्रबंधन हेतु वर्षा के द्वारा एवं नदियों और मेघों को भेदकर जन कल्याण हेतु जल प्राप्त करवाया। आगामी प्रथम मण्डल तैतीसवें सूक्त के दसवें मंत्र में भी बताया गया है कि जो जल द्युलोक से पृथ्वी पर नहीं बरस सके एवं 
जलों के अभाव से भूमि शस्यश्यामला नहीं हो सकी, तब इन्द्र देव ने अपने जाज्वल्यमान वज्र से अन्धकार रूपी मेघों को बेधकर गौ के समान जल का दोहन किया। जल प्रबंधन के विषय में उक्त तथ्य से ज्ञात होता है कि इन्द्र देव अपनी शक्ति सामर्थ्य या किसी यंत्र जैसे वज्ञ आदि से वर्षा करा देते थे। ऋग्वेद के प्रथम मण्डल में इक्यानवें सूक्त के इक्कीस बाईसवें मंत्र के अनुसार सोमदेव को भी जल की उत्पत्ति करने वाला बताया गया है (ग्वेद, 1/91/21-22)।

अश्मास्यमवंत ब्रह्यणस्पतिर्भुधधारमभि यमोज सातृणत्। तमेव विश्वे पपिरे स्वदेशो बहु सांक सिसिचुरूतसमद्रिपम्//

(अग्वेद, 2/24/4)

अर्थात ब्रह्यणस्पतिदेव ने पत्थर जैसे मुख वाले मधुर धाराओं से युक्त मेघों को बलपूर्वक बरसाने के लिए प्रेरित किये एवं वृष्टि के जल का पान सूर्य रश्मियों ने किया तथा प्रचुर जल धारा के रूप में धरती पर बरसाया। उक्त पंक्तियों का आशय यह हैं कि जल की कमी के कारण बृहस्पति भी अपनी शक्ति से मेघों से वर्षा करवाने में सक्षम थे।

\section{प्र सीमादित्यों असुजद्विधर्ता ॠतं सिन्धवो वरूणस्य यन्ति। न श्राम्यन्ति न वि मुचन्त्येते वयो न पत्तू रघुया परिज्मन //}

( ग्वेद, $2 / 28 / 4$ )

यह मंत्र वरूण देव को समर्पित है और इसके अनुसार समस्त विश्व को धारण करने वाले अदिति पुत्र वरूण देव ने जल को वृष्टि के रूप में धारण करके अपनी सामर्थ्य से नदियों को प्रवाहित किया, जो पक्षियों की भांति अविरल गति से पृथ्वी पर विचरण कर रही हैं। तात्पर्य है कि वरूण देव ने जल को वर्षा के रूप में अवतरित करके पृथ्वी की समस्त नदियों को जल से पूर्ण किया जिससे कि धरती पर जल की उपलब्धता बनी रहे और यह कार्य जल प्रबंधन का एक आवश्यक उत्तम कार्य है; क्योंकि जलयुक्त नदियों के बिना जल प्रबंधन का कार्य संभव नहीं हो सकता।

या आपो दिव्या उत वा स्रवन्ति/ खनित्रिमा उत वा या: स्वयंजा//

(ऋगेद, 4/49/2)

इस स्तुति के अनुसार कहा गया है कि हमारी वृष्टि मेघों के द्वारा सम्पन्न हो।

दिवो नो वृष्टिं मरुतो रीधघं प्र पिन्वत वृष्णो अश्रव्यधाराः। अर्वाडेतेन स्तनयितुनेह्यपो निषिजचन्नसुर: पिता न://

(ख्वेद, $5 / 83 / 6$ )

हे मरूद्गणों! आप (निमित) वृष्टि करें। वर्षणशील मेघ की जल धाराएँ हमें पोषण प्रदान करें। हे पर्जन्य देव! आप गर्जनशील मेघ
के साथ जल सिंचन करते हुए हमारी ओर आगमन करें। आप प्राणाकर्षक रूप से हमारे पिता स्वरूप पोषण कर्ता हैं। इस मंत्र के अर्न्तगत स्तुति की गई है कि आप उचित मात्रा में वर्षा करके हमें धन्य करें ताकि प्राप्त होने वाले जल से हम जल प्रबंधन का कार्य पूर्ण रूप से कर सकें।

अद्या चिन्नू चित्तदपो नदीनां यदाभ्यो अरदो गातुमिन्द्र। न पर्वता अद्यासदो न सेदुस्तया दृल्हानि सुक्रतो रजांसि/।

(अवेद, $6 / 30 / 3$ ) अर्थात हे इन्द्र! आपने ही आज भी और पहले भी नदियों के जल को प्रवाहित होने के लिए मार्ग का निर्माण किया है। आपने ही पर्वतों को स्थिर किया और आपने ही सब लोकों को सुदृढ़ किया है।

इस मंत्र के अनुसार, ज्ञात होता है कि नदियों की स्थिति, स्थान और नदियों के मार्गों का निर्धारण भी इन्द्र देव ने ही किया था। नदियों के जल निर्गम मार्गों का निर्धारण जल प्रबंधन के विषय में मुख्य स्थान होता है।

या: सूर्यो रश्मिभिराततान याभ्य इन्द्रो अरदद् गातुमूर्मिम्।

ते सिन्धवो वारिवो धातना नो यूयं पात स्वस्तिभि: सदा न://

(ऋगेद, $7 / 47 / 7$ )

जिस जल को सूर्य देव अपनी रश्मियों के द्वारा बढ़ाते हैं एवं इन्द्र देव के द्वारा जिन्हें प्रवाहित होने का मार्ग दिया गया है। हे सिन्धों! आप उन जल धाराओं द्वारा हमें धन धान्य से परिपूर्ण करें तथा कल्याणप्रद कारणों से हमारी रक्षा करें।

इन पंक्तियों से हमें ज्ञात होता हैं कि जल की मात्रा और नदियों के जल को बढ़ाने हेतु प्रार्थनाएं की गई हैं, जो जल प्रबंधन का एक महत्वपूर्ण अंग है।

शं त आपो धन्वन्या: शं ते सन्त्वनूप्यॉः।

शं ते खनित्रमा आप: शं या: कुम्भेभिराभूता: // (ऋग्वेद, $9 / 1 / 1$ ) अर्थात मरूस्थल के जल, जल सम्पन्न भू-भाग में होने वाले जल, खोदकर प्राप्त किये गये (कुएँ, बावड़ी आदि) जल तथा घड़ों में भरकर लाए गये जल ये सभी प्रकार के जल आपके लिए कल्याणप्रद हो।

जल प्रबंधन के विषय में उक्त श्लोक से ज्ञात होता है कि वैदिक काल में भूमिगत जल का उपयोग कुंओं, बावड़ियों का प्रचलन भी था तथा एक स्थान से दूरस्थ मरूसथलों पर जल ले जाने के लिए इस काल में घड़ों के द्वारा जलपूर्ति की जाती थी।

शं त आपो हैमवती: शमु ते सत्तूत्स्या:।

शं ते सनिष्यदा आप: शमु ते सन्तु वर्ष्या:// (अगेद, $9 / 2 / 1$ ) 
अर्थात- हे साधकों हिम से उत्पन्न जल प्रवाह (झरनें) से प्रवाहित अनवरत् तीव्र वेग से बहने वाले तथा वर्षा द्वारा नदियों में आये जल प्रवाह ये सभी आपके लिए सुखदायी और कल्याणकारी हो अर्थात वैदिक कालीन जल प्रबंधन के अर्त्तगत- हिम, जल, झरनें, वर्षा एवं नदियों के जल को उपयुक्त रूप से उपयोग में लाकर जल प्रबंधन का कार्य किया करते थे।

इमं मे गंगों यमुने सरस्वति शुतुद्रि स्तोमं यचता परूष्णया। असिकन्या मरूद्वृधे वितस्तयार्जीकीये श्रणुह्हा सुषोमया।।

(ऋवेद, $10 / 75 / 5$ ) अर्थात- हे गंगा, यमुना, सरस्वती, शुतुद्री (सतलज) परूष्णी (रावी) असिक्नी (चिनाब) के साथ मरूद्वृधा विस्ता (झेलम), सुषोमा (सोहान) और अर्जीकीया (व्यास) आदि नदियां आप हमारे स्तोत्रों को सुनें। प्रस्तुत श्लोक में नदियों से स्तुति की गई है कि वे अपने पवित्र जल से सदैव ही समस्त पर्यावरण एवं जीव जन्तुओं, वनस्पतियों की रक्षा करें, निरन्तर अविरल बहती रहें और सर्व का कल्याण करें।

ऋग्वेद में चार प्रकार के जलों का वर्णन मिलता हैं (ऋग्वेद, $7 / 49 / 2)$

एक) दिव्या: आपः - आकाश से वृष्टि द्वारा प्राप्त होने वाला जल । दूसरा) खनित्रम् आपः - खोदकर बनाएं गये कुएं एवं बावड़ी से प्राप्त होने वाला जल। तीसरा) स्वयंजा आप: - पहाड़ों, झरनों आदि से प्राप्त होने वाला जल। चौथा) समुद्रार्था आप:अर्थात समुद्रों में मिलने वाली नदियों का जल ।

ऋग्वैदिक काल में मुख्यतः दो प्रकार के स्रोतों के माध्यम से जल प्रबंधन का कार्य किया जाता था-

1) कृत्रिम स्रोतों से- कुएं, बावड़ी, तालाब, कुलियॉ आदि।

2) प्राक्रतिक स्रोतों से- वर्षा का जल, प्राकृतिक तालाबों, नदियों, जलाशयों आदि से प्राप्त होने वाला जल।

वैदिक काल में जल प्रबंधन का महत्वपूर्ण अंग नदियां हैं। तत्कालीन साहित्य ग्रंथों में लगभग 31 नदियों के उल्लेख मिलते हैं, जिनमें 25 नदियां ऋग्वेद काल में उल्लेखित हैं (ऋग्वेद, $10 / 75 / 4)$ | ऋग्वेद काल में नदियों व पर्वतों का परस्पर घनिष्ठ सम्बन्ध होने का उल्लेख भी मिलता है। नदियों से ही नहरें कुल्यां निकाली जाती थी और ये नदियां समुद्र की ओर बहती थी (दामोदर, 1923, पृ. 18-19)। वैदिक कालीन जल प्रबंधन के स्रोतों में नहरों का योगदान अति महत्वपूर्ण था जो दूरस्थ स्थानों पर जल ले जाने में सर्वोत्तम साधन थी। सातवलेकर (1923) के अनुसार, नहरों की कई किस्मों में नदी से
निकाली गईं नहरों का वर्णन भी हमें वेदों से प्राप्त होता है (गुप्ता, 2011, पृ. 190)। जहां नहरों के लिए "वक्षणा" शब्द का प्रयोग किया गया है वहीं नहरों का वर्णन गाय एवं बछड़ें के रूप में भी किया गया है। यथा बछड़े के साथ-साथ जैसे गाय जाती हैं, वैसे ही नदियों से मार्ग बनाकर नहरों में पानी जाता हैं (अथर्ववेद, $3 / 13)$ । नहर में पानी बहाने से पहले धार्मिक अनुष्ठान भी करते हैं तथा इस काल में कुओं के द्वारा भी जल प्रबंधन का कार्य किया करते थे।

अथर्ववेद में भी जल प्रबंधन के विषय में अनेक प्रकार के जल का उल्लेख आता है, जो घरेलू कार्यों, पीने एवं कृषि आदि के लिए भी उपयोग में लाया जाता था (यजुर्वेद, 16/37)। वे हैधन्पन्या: आप: - मरूदेश से प्राप्त होने वाला जल। अनूप्या: आप: - तालाबों आदि से प्राप्त होने वाला जल। खनित्रिमा: आप: - खोदकर बनाये गये कुएं एवं बावड़ी से प्राप्त होने वाला जल।

कुंभे आमृता - घडे में भरकर लाये जाने वाला जल। वर्षिकी: आप: - वर्षा से प्राप्त होने वाला जल।

सिन्धुभ्य: - नदियों से प्राप्त होने वाला जल।

हैमवती: आप: - हिमवान पर्वतों से प्राप्त होने वाला जल। उत्त्या: ते शं उ शन्तु - स्रोतों से प्राप्त होने वाला जल। सनिष्यदा आप: - वेग से बहने वाला जल।

नम: स्तुत्याय च पश्याय च नम: काटयाय च नीप्याय च नमः। कुल्याय च सरस्याय च नमो नादेयाय च वैशनताय च।/

(यजुर्वेद, 16/38)

इस मंत्र के अनुसार मानव को बताया गया है कि नालों एवं जल मार्गो को शुद्ध करने वालों को आप अन्न दें और कूप आदि बड़े जलाशयों एवं कुल्याय नहरों का निर्माण करने वालों को आप अन्न प्रदान करें। अर्थात मानव को चाहिए कि नदियों के मार्गो, बम्बों, कूपों, जलाशयों, बड़े और छोटे तालाबों के जल को संचित करने हेतु नवीन बॉध निर्माण एवं जल प्रबंधन कार्य हेतु पूर्ण सहयोग प्रदान करें।

नम: कुप्याय चावटयाय च नमो वीध्रयाय चातप्याय च नमो। मेघ्याय च विद्युत्याय च नमो वर्ष्याय चावर्ष्याय च।/

(तैत्तिरीय संहिता, $4 / 5 / 7 / 1$ ) अर्थात् मनुष्य कूपादि में कार्यरत भृत्यों का सत्कार करें जो अनेक उत्तम कार्यो को सिद्ध करा सकें। कुँओं एवं बड़े छोटे जलाशयों के निर्माताओं को अन्न दें, प्रोत्साहन दें जिससे वे जल प्रबंधन का कार्य सुचारू रूप से कर सकें। 
शर्मा एवं सहगल

वैदिक समयों में जल प्रबन्धन का उत्कृष्ट समीक्षात्मक स्वरूप जहां ऋग्वेद प्राचीनतम वेद है और यह दस मंण्डलों में विभक्त है; अन्य तीनों वेद- सामवेद, यजुर्वेद तथा अथर्ववेद और उनके उपवेद, वेदांग, उपनिषद्, स्मृतियां, दर्शन आदि विभिन्न धर्म ग्रंथों में भी उस समय की आध्यात्मिक, सामाजिक एवं आर्थिक व्यवस्थाओं का विस्तृत वर्णन मिलता है, वहीं जल प्रबंधन की समुचित और पर्याप्त व्यवस्था का विवरण भी हमें उक्त ग्रथों से ही प्राप्त होता है। इस प्रकार वैदिक कालीन समाज जल की आपूर्ति हेतु प्राकृतिक एवं क्रत्रिम स्रोतों के माध्यम से जल प्रबन्धन कर विषम परिस्थितियों में भी अपनी आवश्यकताओं की पूर्ति करता था। प्राकृतिक स्रेतों में मुख्यतः वर्षा, नदी, झीलें, झरनें प्राकृतिक तालाबों एवं जलाशय आदि स्रोत आते थे। कृत्रिम स्रोतों में कुएं, तालाब, नहरें, जलाशय आदि स्रोत आते थें (गुप्ता, 2011, पृ. 181)। इस काल में घरेलू जल प्रबंधन एवं दैनिक कार्यों के लिए मुख्यतः कुएं, घड़े, नदियों, तालाबों, बावली आदि स्रोतों से जलापूर्ति करते थे जबकि कृषक कृषि में सिंचाई हेतु अधिकांशतः वर्षा के जल पर ही निर्भर रहते थे। वेदों में अनेक स्थानों पर वर्षा में सिंचाई के उल्लेख मिलते हैं (गुप्ता, 2011, पृ. 181)।

वैदिक साहित्य में वर्षा के लिए वृष्टि शब्द आया है। वास्तव में पृथ्वी पर जल का स्वाभाविक स्रोत वर्षा का जल ही है। अतः वर्षा-जल से भूमिगत जल, तालाबों, नदियों एवं पहाड़ों की चटाानों और हिम-पर्वतों को भी जल प्राप्त होता है। यही कारण हैं कि वेदों में स्थान-स्थान पर वर्षा के लिए देवताओं से प्रार्थनाएं की गई हैं। ऋग्वेद तथा वैदिक साहित्यों में वर्षा का सीधा सम्बन्ध इन्द्र से तथा वर्षा प्राप्ति हेतू इन्द्र से प्रार्थनाएं, इस बात की द्योतक हैं कि जल प्रबंधन का कार्य भी अति महत्वपूर्ण था (ऋग्वेद, $7 / 49 / 1$ )। वैदिक काल में वर्षा जल को जीवन का आधार भी बताया गया हैं (ऋग्वेद, $7 / 102 / 1 ; 4 / 47 / 2$; $5 / 63 / 2$ ) । वैदिक युग के इस कथन से भी स्वमेव सिद्ध है कि जल ही जीवन है जिसका दुरूपयोग असहय तथा सर्वथा वर्जित है। अतिरिक्त इसके, जल प्रदूषित करने का सीधा अभिप्रायः है जीवन लीला का समापन। ऋग्वेद में आख्यान आया है कि इन्द्र वृष्टि को रोकने वाले दैत्य को मारकर वर्षा कराते हैं और नदियों को प्रगतिशील बनाते हैं (ऋग्वेद, $1 / 42 / 46 ; 3 / 33 / 6$; $10 / 50 / 3)$ ।

हड़प्पा सभ्यता और वैदिक साहित्य नामक अपने ग्रन्थ में सिंह (1987) ने लिखा है कि ऋग्वेद और सम्पूर्ण वैदिक काल में वर्षा नहीं होने की चिंता दिखाई गई है क्योंकि इस काल में किये जाने वाले यज्ञों का मुख्य विधान अग्नि व इन्द्र की आराधना मात्र वर्षा कराने हेतू ही था (पृ. 97-98)।

यजुर्वेद में भी अनेक स्थानों पर वर्षा के महत्व पर प्रकाश डाला गया है। यजुर्वेद में भी इच्छा के अनुसार वर्षा कराने हेतु प्रार्थनाएं की गई हैं (यजुर्वेद, 22/22)।
अथर्ववेद में जल के विभिन्न प्रकार एवं वर्षा जल के गुणधर्मों एवं जल प्रबंधन हेतु चितंन के दिशा-निर्देश दिये गये हैं। अथर्ववेद के प्राण सूक्त में जल ही जीवन हैं (अथर्ववेद, $7-8$ ) एवं जल चक्र का भी वर्णन हैं (अथर्ववेद, 11/4)।

श न आंपो धन्वन्या: शमु सन्त्वनूप्या:। श न: खनित्रिमा आप: शमु या: कुम्भ आभृता: शिवा ना सन्तु वार्षिकी:// (गुप्ता, 2011, पृ. 189)। अर्थात जो जल बाहर से प्राप्त होता है, वह घर में लाकर घड़ों में रखने के कारण उसके गुण धर्म में बदलाव आता है। गुणवत्ता के विषय में इन पंक्तियों से ज्ञात होता है कि उस समाज के लोग जल के विषय में कैसे चिंतन एवं शोध कार्य करते थे। अर्थात कुओं के माध्यम से प्राप्त किया गया जल भी कुछ समय के पश्चात् उसके गुणों का ह्वास होने लगता है और यह सिद्ध करना बिना शोध कार्य के संभव नही है; अर्थात वैदिक काल से ही जल की गुणवत्ता की जांच परख की जाती थी। इस सूक्त में जल संबधित गुणों एवं प्राप्ति की विस्तृत रूप से चर्चा की गई है।

\section{वैदिक कालीन जल प्रबंधन की आधुनिक परिप्रेक्ष्य में समीक्षा}

सृष्टि संरचना के पंच तत्वों में जल का स्थान महत्वपूर्ण है। वेदों में जल को पवित्र, पूजनीय, लौकिक, औषधीय, जीवन दाता माना गया है। यह धारणा और सच्चाई जल प्रबंधन का अभिन्न अंग है। आधुनिक काल में बढ़ता हुआ जल संकट भारत के लिए ही नहीं वरन् सम्पूर्ण संसार के लिए एक महत्वपूर्ण चुनौती है। इससे निपटने के लिए हम अपने अतीत वैदिक काल में किये गये जल प्रबंधन के कार्यों से सीख लेकर इस विकराल संकट से छुटकारा पा सकते हैं।

वैदिक काल में मुख्यतः जल प्रबंधन के अर्त्तगत जल संरक्षण पर लोगों का अत्याधिक ध्यान आकर्षित किया है। प्राकृतिक स्रोतों में वर्षा, बड़े-बड़े जलाशय, झीलें, प्राकृतिक विशाल तालाबों को उपयोग में लाया जाता था एवं कृत्रिम स्रोतों का निर्माण कार्य किया जाता था। सामूहिक रूप से जब पर्याप्त मात्रा में कृत्रिम विशाल तालाबों एवं कपों का निर्माण होता रहा है तो भारी वृष्टि में तल पर बहने वाले जल की तेज गति तालाबों एवं कूपों में संभरण के कारण स्वतः ही नियंत्रित होती है। इस प्रकार मिट्टी का कटाव नहीं होता और तालाबों में जल पर्याप्त मात्रा में आगामी वर्षों हेतु सुरक्षित रहता है और जल का भूगर्भीय स्तर भी स्थिर बना रहता है। इससे कूपों में जल परिपूर्ण तथा सदैव स्थिर रहेगा और तभी जन, जल, धन, मिट्टी की बचत होगी। इन महत्वपूर्ण बिन्दुओं के कियान्वयन से आधुनिक काल में भी अरबों रूपये प्रति वर्ष बचाये जा सकते हैं। जल संकट के इस विकराल रूप से मुक्ति मिल सकती है। भारत में गंगा युमना एवं अन्य नदियों की स्वच्छता पर प्रति वर्ष खर्च बढ़ रहा है और परिणाम शून्य हैं। जनसंख्या वृद्धि, भारी औद्योगिकीकरण, 
जागरूकता की कमी और ग्लोबोलाइजेशन वार्मिंग ने शुद्ध जल की कमी को और बढ़ावा दिया है; जबकि शुद्ध जल जीवन की मूलभूत आवश्यकता है। अतः वर्तमान में जल स्तर के प्रति वर्ष तेजी से नीचे जाने से कृषि की सिंचाई में भी कमी आ रही है। इन परिस्थितियों को देखते हुए यह और भी आवश्यक हो जाता है कि हमें वैदिक कालीन जल प्रबंधन के समस्त तरीकों को वर्तमान में अपनाना होगा। सम्पूर्ण राष्ट्र में प्राचीन भारतीय यज्ञ द्वारा वर्षा कराने की विधि पर अन्वेषण करकें यज्ञ क्रिर्यान्वित कराना, कृत्रिम और विशाल मात्रा में पर्याप्त तालाबों का निर्माण करके समाज में जल पूजा के महत्व को समझाना, समाज को सामाजिक रूप से जागरूक करके, जल दूषित करने वालों को कड़ी सजा का प्रावधान करके, और सम्पूर्ण समाज की सहभागिता के माध्यम से जल प्रबंधन का कार्य करना, भारत ही नही वरन् सम्पूर्ण संसार को जल संकट से निजात दिला सकता है।

\section{निष्कर्ष}

अन्ततः हम कह सकते हैं कि वैदिक काल में जल प्रबंधन हेतु कृत्रिम तथा प्राकृतिक स्रोतों के माध्यमों से जलापूर्ति होती थी। वैदिक काल आध्यात्मिक काल होने से भी इसमें जल की पूजा, वर्षा कराने के आख्यान, यज्ञों के द्वारा पवित्र जल की उत्पत्ति, एवं जल महत्व, औषधि एवं अमृत के रूप में जल का विशिष्ट स्थान होना भी जल प्रबंधन को सुदृढ़ता प्रदान करता रहा है। जल देवताओं के विभिन्न स्वरूप एवं मुख्य रूप से ऋग्वैदिक काल में जल प्रबंधक के रूप में इन्द्र को प्रत्यक्ष रूप से प्रेक्षित किया गया है। अतः वैदिक कालीन समाज जल प्रबंधन हेतु सदैव ही चिंतित एवं प्रगतिशील रहा है। तत्कालीन समाज में जल की गुणवत्ता एवं पर्याप्त मात्रा के विषय में जल प्रबंधन चर्मोत्कर्ष व शिखर पर विराजमान था। आज जल प्रबन्धन हेतु सभी राष्ट्र अनेकों अत्याधुनिक प्रोद्योगिक संसाधनों द्वारा प्रयत्नरत अवश्य हैं किन्तु शुद्ध पेयजल संभरण और संरक्षण की समस्या सबसे बड़े विकराल रूप में विश्वव्यापी समस्या बनी है। अतः जल प्रबन्धन हेतु वैदिक युग के अर्वाचीन प्राकृतिक संसाधनों का वर्तमान में सामजस्य करना मानव के लिये हितकर ही होगा।
राकेश कुमार शर्मा, पी-एच.डी0., प्राध्यापक; महेश कुमार सहगल, शोधार्थी, प्राचीन भारतीय इतिहास, संस्कृति एवं पुरातत्व विभाग, गुरूकुल कांगड़ी विश्वविद्यालय, हरिद्वार, उत्तराखण्ड, भारत।

\section{संदर्भ सूची}

खन्ना, विजय (2013). जल संरक्षण, प्रबंधन एवं जल जागरूकता/ दिल्लीकिताब घर प्रकाशन ।

गुप्ता, देवेन्द्र कुमार (2011). वैदिक कृषि विज्ञान/दिल्ली- प्रतिभा प्रकाशन।

दामोदर, सातवलेकर (1923). वेद में कृषि विधा। स्वाघ्याय मंडल औध, पब्लिसर सातारा।

पटेरिया, वर्षा एवं अग्रवाल, विपिन (2013). प्राकृतिक जल स्रोत, प्रदूषण एवं संरक्षण/दिल्ली- शिवांक प्रकाशन ।

मिश्रा, श्याम नारायण (2011). जल हमारा कल/ राजस्थान- कपिल प्रकाशन।

मणि, दिनेश (2008). जल संसाधन एवं प्रबंधन/ नवसाक्षर प्रकाशन दिल्ली।

शास्त्री, ज्ञान प्रकाश (2004). वैदिक साहित्य में जल तत्व/ नई दिल्लीपरिमल पब्लिकेशन।

सिंह, भगवान (1987). हड़प्पा सभ्यता और वैदिक सभ्यता। नई दिल्लीराधाकृष्ण प्रकाशन।

ऋग्वेद, $1 / 23 / 19-20 ; 1 / 32 / 1 ; 1 / 91 / 21-22 ; 1 / 42 / 46$; $2 / 24 / 4 ; \quad 2 / 28 / 4 ; \quad 3 / 33 / 6 ; 4 / 33 / 7 ; \quad 4 / 47 / 2 ; 4 / 49 / 2 ;$ $5 / 63 / 2 ; \quad 5 / 83 / 6 ; 6 / 30 / 3 ; 7 / 47 / 7 ; 7 / 49 / 1-2 ; 7 / 102 / 1$; $7 / 110 / 39 ; 9 / 1 / 1 ; 9 / 2 / 1 ; 10 / 50 / 3 ; 10 / 50 / 31 ;$ $10 / 75 / 4-5 ; 10 / 105 / 3$;

यजुर्वेद, $16 / 37-38 ; 22 / 22$

अथर्ववेद, $3 / 13 ; 7 / 8 ; 11 / 4$

तैत्तिरीय संहिता, $4 / 5 / 7 ; 7 / 14 / 3$ 